\title{
Development and evaluation of CARIES-QC: a caries-specific measure of quality of life for children
}

\author{
Fiona Gilchrist ${ }^{*}$, Helen D. Rodd, Chris Deery and Zoe Marshman
}

\begin{abstract}
Background: Existing paediatric oral health-related quality of life (OHRQOL) measures are generic instruments designed to evaluate a range of oral conditions. It has been found that disease-specific measures may be more adept at detecting subtle changes which occur following treatment of the condition in question. Furthermore, existing self-report OHRQoL measures have not involved children at all stages of development of the measure. The aim of this study was to develop a caries-specific measure of quality of life for children.
\end{abstract}

Methods: The first stage of the study involved a qualitative enquiry with children, aged 5-16years, to inform the development of the measure. Children generated the potential items, contributed to item reduction and questionnaire design and participated in the testing of face and content validity. The resulting measure was evaluated in a crosssectional validation study. Ethical approval was granted for the study.

Results: The qualitative study found that children discussed a number of caries-related impacts which affected their daily lives. These were incorporated into a draft measure which was further refined following testing of face and content validity. This resulted in the production of the Caries Impacts and Experiences Questionnaire for Children (CARIES-QC), comprising 16 items and one global question. Two hundred participants with a mean (range) age of 8.1 (5-16) years took part in the further evaluation of CARIES-QC. Four items, which did not fit the Rasch model, were removed from further analysis. The remaining 12 items demonstrated good internal consistency (alpha $=0.9)$ and the total score showed significant correlations with the number of decayed teeth, presence of pain, pulpal involvement, the Child Perceptions Questionnaire (16-item short form) and the global score $(p<0.01$, Spearman's rho).

Conclusion: In conclusion, children's input allowed the development of a valid and reliable child-centred cariesspecific quality of life measure. CARIES-QC can now be used to evaluate which interventions for dental caries are most effective in reducing impacts from the child's perspective.

Keywords: Child, Dental caries, Quality of life, Qualitative research, Outcome assessment

\section{Background}

Dental caries remains a global public health concern. A recent systematic review reported that approximately 621 million children have untreated dental caries [1]. Despite its worldwide prevalence, little attempt has been made to seek children's own accounts of how this disease impacts on their daily lives.

\footnotetext{
* Correspondence: f.gilchrist@sheffield.ac.uk

School of Clinical Dentistry, University of Sheffield, Claremont Crescent, Sheffield S10 2TA, England
}

The main focus of studies on the impact of dental caries in children has, not surprisingly, been to determine the prevalence of dental pain in child populations. Whilst pain is clearly an important sequelae of caries, consideration should also be given to the wider psychosocial aspects of this universal disease. Findings from previous studies using oral health-related quality of life measures (OHRQoL) have shown that children with dental caries frequently report functional impacts such as difficulty eating, drinking and pain when brushing teeth [2-6]. In addition to these functional concerns, children with caries also report wider psychosocial impacts related to smiling, 
playing, difficulty sleeping or relaxing, emotional/social wellbeing and schoolwork [2, 3, 7].

However, the relationship between clinical caries data (e.g. extent) and child OHRQoL has been found to be weak and inconsistent [8-12]. Several explanations have been suggested to account for this finding, including: limitations of existing child measures of OHRQoL [13]; analysis of child populations with relatively low levels of disease, and the effects of socioeconomic status, cultural differences and general health which may all mediate the impacts [11, 14-16].

One of the limitations of existing self-report OHRQoL questionnaires is that they are 'generic' measures meaning they are designed to capture the impacts of all oral conditions on children's lives. Wiebe and co-workers (2003) found that in randomised controlled trials with a true underlying therapeutic effect, disease-specific instruments were more responsive to change in health related quality of life than were generic instruments [17]. Therefore, while generic measures are useful to compare populations and can be used to compare groups with different health conditions, disease-specific measures are more adept at measuring changes in individuals with a specific disease.

Furthermore, inherent limitations of existing self-report measures for evaluating OHRQoL in children with caries, (i.e. Child Perceptions Questionnaire, Child-Oral Impacts on Daily Performances index, and Child Oral Health Impact Profile) have been highlighted by a recent systematic review [13]. Firstly, methods adopted to develop these measures included children only at the latter stages of item development, therefore the included items may not fully reflect the language and range of impacts experienced by children.

Secondly, the measurement properties of the existing measures had not been evaluated according to the required standards suggested by the Consensus-based Standards for the Selection of Health Measurement Instruments initiative (COSMIN) [18]. However, it is acknowledged that the measures included in this 2014 systematic review were all developed prior to the existence of the criteria used to assess them, which may account for some of the deficiencies identified. Since this review was undertaken, further studies have been published which have used item response theory (IRT) methods with existing measures and have recommended changes based on their findings [19-21]. Others have measured responsiveness of the existing self-report measures. However, none of these studies investigated correlations between change scores and the global transitional judgement question to confirm responsiveness, as recommended by the COSMIN group [22-25].

In order to address these acknowledged limitations, a caries-specific quality of life measure, which has involved children at all stages in its development and is sensitive to changes resulting from interventions to manage dental caries is required. Such a measure would have important applications in future clinical trials which seek to prevent or manage caries.

The aim of this study therefore was to develop and validate a caries-specific measure of quality of life 'CARIES-QC' for children which could be used to evaluate different approaches for the management of dental caries. The objectives were to:

1. Involve children in the design and content of the measure to ensure that it is meaningful and relevant to them.

2. Evaluate the properties of the measure including validity, reliability and responsiveness.

\section{Method}

The measure was developed based on the definition of OHRQoL as proposed by Locker and Allen (2007) to encompass "the impact of oral diseases and disorders on aspects of everyday life that a patient or person values, that are of sufficient magnitude, in terms of frequency, severity or duration to affect their experience and perception of their life overall" [26]. The measure was developed using the robust methodology proposed by Guyatt and coworkers (1986) [27]. A seven-step process was used as recommended, involving: item generation; item reduction; questionnaire design; testing of face and content validity, and testing of validity reliability and responsiveness (Fig. 1). Each of these steps will be described in turn. The methodology was child-centred and the measurement properties were evaluated using both classical test theory and item response theory. Ethical approval was granted by the South Yorkshire Research Ethics Committee (Reference number: 11/H1310/3).

\section{Development of CARIES-QC}

This part of the investigation comprised four stages (Fig. 1). Children aged 5-16 years who could speak English with active caries or who had treatment of dental caries in the preceding year were invited to participate. Clinical and demographic data were collected including: age; gender; ethnicity; postcode (to assign Index of Multiple Deprivation (IMD) score/rank); dmft/DMFT; presence of anterior caries; pain and pulpal involvement. DMFT/dmft was assessed by FG using a combination of clinical and radiographic evidence where available. Caries was judged to be present where caries had extended into dentine either clinically and/or radiographically. The exception to this was that both children with and without caries experience were asked to comment on the questionnaire design and face validity as detailed below. Exclusion criteria included children with pre-existing significant medical conditions, other dental conditions (trauma, dental 


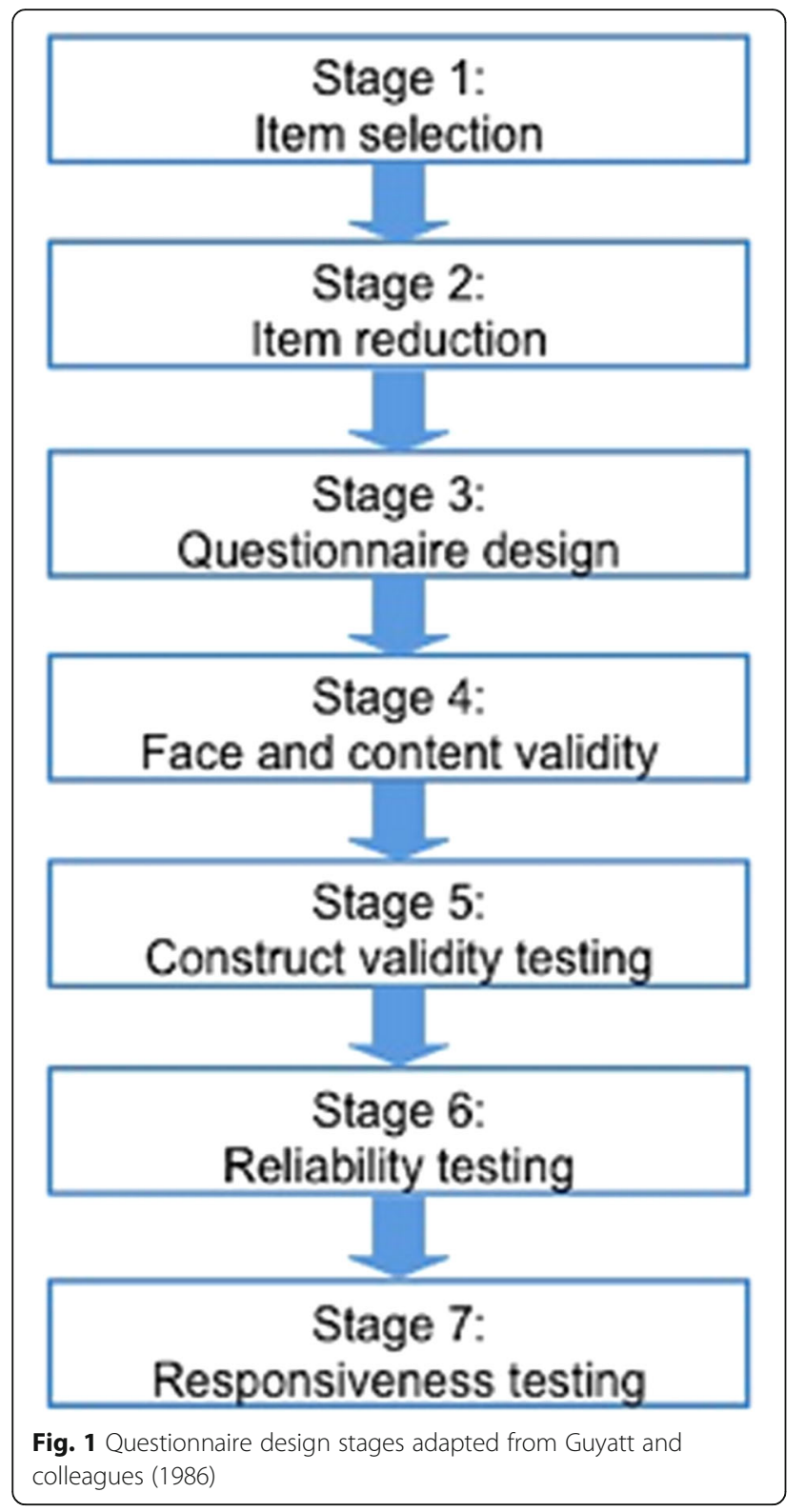

anomalies), or those with severe learning difficulties who would be unable to participate with the intended activities even with support.

\section{Stage 1: Item generation}

The aim of this stage was to generate potential items for the measure and to identify the language children used to describe impacts that they experienced as a result of dental caries. Children were purposively sampled from both a primary care dental setting (Firth Park Clinic, Sheffield Salaried Dental Services \{FPSDS\}) and a secondary dental care service (Paediatric Dental Department at the Charles Clifford Dental Hospital $\{\mathrm{CCDH}\}$, Sheffield) to take part in qualitative focus groups and interviews. Recruitment continued until data saturation was achieved [28]. Further details of this initial qualitative phase in the development of CARIES-QC have been previously reported [29].

The sociology of childhood guided the conduct and analysis of the focus groups and interviews [30]. This approach regards children as capable experts in their own lives and gives them a voice as research participants. In order to achieve this and to prioritise the child's voice, the analysis took a narrative approach. That is, rather than trying to "verify" what children said, the focus was on how they described their experiences and what they meant to them [31]. A total of 20 children participated in this stage. Interviews ( $n=15$, conducted by FG) and focus groups ( $n=2$ with 5 children, facilitated by FG and ZM) were held with children aged 5-13 years (12 male, 8 female) who had a wide range of clinical presentations. The majority $(n=17)$ were white British and 11 children lived in areas ranked as the most deprived quintile in the UK (Table 2). Details of the children's clinical presentations are reported elsewhere [29].

Framework analysis was used to classify the data according to themes and categories that emerge from the data. This technique has developed from social policy research to facilitate handling large volumes of data [32]. The analytical approach involved the following stages [33]:1. Identifying initial themes; 2 . Labelling the data; 3 . Sorting the data by theme and 4. Synthesising the data. Further details of this analysis have been published elsewhere [29].

Using this approach, 17 different items, shown in Table 1, were described by children. It was decided that the response options "a bit", "a little", "sometimes", "very much" and "a lot" would be initially adopted as these descriptors had been most commonly used by participants during conversations. The next stage of the project (see below) aimed to verify which of these words would be most suitable in the final response format.

Table 1 Items generated from initial interviews and focus groups Potential items following analysis of interviews

- Pain (hurts)

- Difficulty eating some foods

- Having to eat on one side

- Getting food stuck in teeth

- Being kept awake by pain

- Feeling annoyed

- Having to take medicine

- Pain during toothbrushing

- Having to eat more slowly

- Having to eat more carefully

- Crying

- Front teeth looking brown

- Feeling tired

- Not being able to do schoolwork

- Difficulty talking

- Feeling grumpy

- Not been able to do normal activities 


\section{Stage 2: Item reduction}

The aim of this stage was to ascertain which caries-related items were most relevant to children and to identify if there were any additional items which should be included. During January and February 2014, 25 children attending $\mathrm{CCDH}$ who were having treatment for caries, were identified and 22 were recruited to Stage 2 of the project. Previous studies have used samples of over 75 participants for this stage, where there have been a large number of items generated [34-36]. As items were to be deleted from the questionnaire following Rasch analysis, item reduction in this study was more limited and with a smaller sample, allowing in-depth discussion of the potential items with participants. Two children declined to participate as they had become distressed during radiographic examination and one family declined due to time constraints. Characteristics of these participants are shown in Table 2.

Children were shown cards depicting the items identified from the item generation stage (Table 1), and they were asked to indicate which ones they had experienced, if any. They were also invited to say which item/s had been the most severe and which they had experienced the most frequently. The mean number of caries-related impacts was six, with a range of zero to 12 . Only one child had not experienced any of the impacts listed, and indeed had not suffered any symptoms or negative effects as a result of his caries. 'Pain', 'getting food stuck in their teeth' and 'having to eat carefully' were the items which had affected most children $(n=16,72.7 \%)$. 'Pain' was also reported as being the most severe impact. In contrast, 'getting food stuck' was the impact which reportedly occurred most frequently. Seven children (31.8\%) could not identify what had been the worst impact and seven children (31.8\%) could not identify which impact had happened most frequently.

'Having difficulty talking' and 'not been able to do normal activities' were endorsed the least. Since these two items were not chosen as having the highest impact or occurring with the greatest frequency, it was decided to omit them from the measure as per Guyatt and co-workers' recommendations [27]. The remaining 15 items were taken forward to the next stage for evaluation of face and content validity. Following the completion of this stage, draft questionnaires were developed to prompt discussions in the questionnaire design stage.

\section{Stage 3: Questionnaire design}

This stage aimed to discover which words were most suitable as the response format, to ascertain children's preferences for the question layout and design and to check the wording of the instructions. Ten participants were recruited in January 2014 either from CCDH or a local general dental practice (Table 2). These one-to-one interactive sessions were audiotaped (Olympus Digital Voice Recorder WS-812) and transcribed verbatim. Recruitment continued until data saturation was achieved. Children were asked which of the descriptors "not at all", "a bit", "a little" "a lot", "sometimes" and "very much" they preferred and they were asked to rank them from worst to best. Most children felt that "a bit" and "a lot" were words that they used most often with their friends and all were able to consistently rank these in the correct order.

Children were then asked to complete six pilot questions using two different formats, to identify their preferences (Additional file 1). Several suggestions were made to improve the clarity and wording of the questions and instructions. These suggestions can be viewed in Additional file 1.

In keeping with the children's suggestions, the final measure therefore invited participants to circle one of three response options: "not at all", "a bit" and "a lot".

\section{Stage 4: Face and content validity}

This stage aimed to ensure that no important items had been omitted and that children interpreted the questions as intended. A total of eight children (with and without caries) took part in the analysis of face validity and 25 children with active caries or caries experience took part in analysis of content validity, including two children with learning disabilities. Recruitment continued until saturation was achieved. Participant characteristics are

Table 2 Characteristics of participants in development stage

\begin{tabular}{|c|c|c|c|c|c|c|c|c|}
\hline \multirow[t]{2}{*}{ Study stage } & \multicolumn{2}{|c|}{ Gender } & \multirow{2}{*}{$\begin{array}{l}\text { Mean (range) } \\
\text { age (years) }\end{array}$} & \multicolumn{5}{|c|}{ Deprivation quintile } \\
\hline & Male & Female & & 1 & 2 & 3 & 4 & 5 \\
\hline Item generation $(n=20)$ & 11 & 9 & $9.55(5.5-13.9)$ & 1 & 2 & 4 & 2 & 11 \\
\hline Item reduction $(n=22)$ & 9 & 13 & $9.40(4.8-15.7)$ & 3 & 1 & 4 & 2 & 12 \\
\hline Questionnaire design $(n=10)$ & 7 & 3 & $9.9(6.4-15.5)$ & 4 & 3 & 3 & 0 & 0 \\
\hline Face validity only $(n=4)$ & 1 & 3 & $10.84(8.8-11.96)$ & 2 & 2 & 0 & 0 & 0 \\
\hline Face and content validity $(n=4)$ & 4 & 0 & $9.45(6.45-12.5)$ & 0 & 1 & 0 & 0 & 3 \\
\hline Content validity only $(n=21)$ & 8 & 13 & $8.24(5.19-14.35)$ & 1 & 2 & 2 & 4 & 13 \\
\hline Overall $(n=81)$ & 29 & 32 & $9.17(4.82-15.72)$ & 11 & 11 & 13 & 8 & 46 \\
\hline
\end{tabular}

Deprivation quintile: $1=$ least deprived and $5=$ most deprived 
shown in Table 2. Children attending CCDH or FPSDS in March 2014 were consecutively recruited to this stage of the investigation. All children who were invited to participate agreed to take part. The testing took an iterative approach, with amendments made during the period of testing to allow these changes to be subsequently evaluated by other children.

Children were asked to complete the questionnaire and discuss why they had chosen their answer, so that their comprehension of the question could be confirmed. This approach has previously been used with both adults and children to explore face and content validity of health-related quality of life measures [37, 38]. Several insightful suggestions were made by participants. These included the addition of a question relating to being able to see holes in teeth; adding "black" as well as "brown" to reflect tooth colour and "grumpy" was changed to "cross" as this was more indicative of how they felt. Further minor amendments were made but no further items were added and no items were felt to be irrelevant.

The global question was based on the one used in the Child Perceptions Questionnaire: "Overall, how healthy are your teeth?" [36] with the response options "Not healthy", "A bit healthy" and "Very healthy". This was modified following testing as it became clear that the participants were not answering this question as expected. As this question had poor face validity, two further global questions were tested with children and the preferred one included in the final version of the measure.

The resultant 16-item measure took approximately 2-5 min to complete depending on the reading ability of the child, with some younger children requiring assistance to read it. CARIES-QC, including the instructions which are intended to be read with a parent, has a Simple Measure of Gobbledygook (SMOG) index of 5.3 and a Flesch-Kincaid grade score of 1.5 indicating a reading age of 6-10 years (http://www.editcentral.com/gwt1/ EditCentral.html).

\section{Evaluation of the measure}

As recommended by the COSMIN group, Rasch analysis, a form of item response theory, was used in the development of CARIES-QC. Rasch provides one mathematical model to guide the production of a linear scale which enables accurate calculation of change scores and therefore is suitable for measurements relating to health interventions [39]. The measure was also evaluated using classical test theory. This part of the investigation comprised three stages (Fig. 1).

\section{Stages 5, 6 and 7: Validity, reliability and responsiveness Recruitment}

A consecutive sample of participants was recruited from new patient clinics in the paediatric dental department of $\mathrm{CCDH}$ and from FPSDS. Participants who understood spoken English aged 5-16 years with active dental caries were recruited between July 2014 and January 2015. The same exclusion criteria were applied as used during the development stage and the same clinical and demographic data were collected. Parents were advised that they could help the child to read the questions if required but that it was the child's responses which were desired.

\section{Questionnaires}

Data were collected at three time points where possible. These were:

- Baseline (T0), for example, at a new patient clinic appointment

- Prior to the start of dental treatment to allow test-retest reliability (T1)

- Following a course of dental treatment for the management of dental caries (T2)

\section{Baseline responses (T0)}

At T0, participants were asked to complete two questionnaires: $\mathrm{CPQ}_{11-14}$-ISF:16 and CARIES-QC. The $\mathrm{CPQ}_{11-}$ 14-ISF:16 contains 16 items and two global questions [40]. Participants are asked how often (never, once or twice, sometimes, often, every day or almost every day) they have experienced the listed impacts during the past 3 months. The questions are scored on a 5-point Likert scale from 0 to 4 , with increasing score indicating increasing frequency of impact (total score possible ranges from 0 to 64). The higher the score, the poorer the rating of OHRQoL. This version of the short form of the $\mathrm{CPQ}_{11-14}$ has been used successfully in children aged 5-8 years despite being originally developed for older children [41].

The initial version CARIES-QC contains 16 items and one global question. The items are scored on a 3-point Likert scale ("Not at all"; "A bit" and "A lot") and scored $0-2$ with increasing score indicating increasing severity of the impact. A higher total score indicates increased impact. Participants were randomised (randomizer.org) to receive either Questionnaire A (CARIES-QC followed by $\mathrm{CPQ}_{11-14-\mathrm{ISF}: 16)}$ or Questionnaire $\mathrm{B} \quad\left(\mathrm{CPQ}_{11-}\right.$ 14-ISF:16 followed by CARIES-QC) to control for order effect. This approach was adopted to ensure that the order in which the questionnaires were administered had no effect on the overall scores for each measure. For test-retest reliability, participants who returned for a prevention visit prior to treatment were asked to complete CARIES-QC once more. This questionnaire, used for test-retest reliability and post-treatment, contained a supplementary global transitional judgment (GTJ) question which asked whether the participant's teeth felt "the same", "better" or "worse" compared to the time of the previous administration. Only those who 
reported that their oral condition had remained stable were included in analysis of test-retest reliability.

\section{Data analysis}

The RUMM2030 (RUMM Laboratory Pty Ltd., Perth, Australia) software was used for all Rasch analyses, which were based on the unrestricted or partial credit model [42, 43]. All other analyses were undertaken using SPSS 20 (IBM, New York, United States). The Index of Multiple Deprivation score/rank (2010) was calculated using GeoConvert applied to the participant's postcodes [44].

\section{Missing items}

Where more than two questions were unanswered in CARIES-QC, the participant was eliminated from further analysis. Where more than two values were missing from

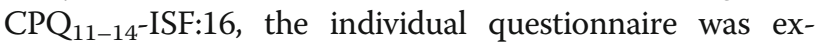
cluded from further analysis. Where less than two missing values were noted, the missing value was replaced with the computed mean of the participant's completed items [45]. This was not required for the Rasch analysis, as the calculations take account of missing values and therefore mean values were not substituted.

\section{Analysis using the Rasch model}

Rasch analysis was performed for the data pertaining to the initial administration of CARIES-QC. According to this method, the items chosen for the final measure should be unidimensional, free from differential item functioning (DIF), i.e. they function in the same way across groups, and fit the model expectations [46]. A sample size of at least 150 participants is recommended to give $99 \%$ confidence that the estimate is within 0.5 logits [47].

The measure was tested with the unrestricted or partial credit model, using the method suggested by Tennant et al. (2007) involving [46]:

1. Category discrimination, this analysis seeks to assess whether participants are able to discriminate between the different response options. Where these were found to be disordered, the question was removed, as CARIES-QC has a 3-point response scale and collapsing of adjacent categories is not appropriate.

2. Local dependency, this was deemed to be present if residual correlations were greater than 0.2 above the average residual correlation [48].

3. DIF was analysed by age (5-7 years, $8-11$ years and 12-16 years), gender, ethnicity (White British or non-White British) and deprivation (three equal groups created from IMD scores).

4. Item fit to the model, if the data fit the Rasch model, each item and person fit residual should be within the range \pm 2.5 and the mean item and person fit statistics should be close to zero with a standard deviation of one [48]. Finally, the individual items and summary chi-square interaction statistics should be non-significant $(P>0.05)$, although these are subject to Bonferroni adjustment based on the number of items. Strict unidimensionality was then examined using an independent $\mathrm{t}$-test on two subsets of items identified using principal component analysis of the item residuals.

5. Reliability was evaluated using the Person Separation Index (PSI). This is equivalent to Cronbach's alpha, however the logit value is used instead of the raw score. It is interpreted in the same manner, i.e. a value of greater than 0.7 indicates good internal consistency.

As CARIES-QC focuses on attributes which are not directly measurable, such as pain and emotional impacts, the raw score will only be indicative of a rank along the scale, this precludes simple addition and subtraction of raw scores $[49,50]$. In order, to use the raw score to accurately measure change, conversion to an interval level scale is required. This can be achieved by transforming the ordinal score to a logit score [50]. All further analyses, where appropriate, were based on the scale created from this analysis.

\section{Interpretability}

Floor and ceiling effects were defined as present if more than $15 \%$ of participants reported the best or worst possible score [51]. The mean, range and standard deviation (SD) of scores were calculated for all subgroups (gender, age, ethnicity and deprivation group). Independent $t$-tests and one-way ANOVA were used to test for differences between the transformed interval CARIES-QC score (CIS) according to clinical and demographic variables as these data were normally distributed.

\section{Internal consistency, reliability and construct validity}

In addition to the Rasch analysis, to allow comparison with similar scales, Cronbach's alpha was calculated for

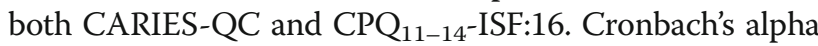
of $>0.7$ is accepted as indicating a homogenous scale [51].

The intraclass correlation coefficient (ICC) was calculated for all participants who remained stable between T0 and $\mathrm{T} 1$. A value $>0.7$ is deemed to indicate acceptable internal reliability [51].

A one-way ANOVA was performed to check for order effect (between Questionnaire A and B). Construct validity was tested using the appropriate bivariate correlations between CARIES-QC total score and: $\mathrm{CPQ}_{11-14}$-ISF:16 total score; the presence of pain; pulpal involvement; anterior caries; total number of carious teeth; total caries experience and the global scores of both CARIES-QC and $\mathrm{CPQ}_{11-14}$-ISF:16. To assess convergent construct validity 
it was hypothesised that there would be positive correlations with $\mathrm{CPQ}_{11-14}$-ISF:16 (especially for oral symptoms, functional and emotional wellbeing domains) and the global questions from both CARIES-QC and CPQ ${ }_{11-}$ ${ }_{14}$-ISF:16. It was also hypothesised that there would also be positive correlations between CARIES-QC total score and clinical data (the total number of carious teeth, the presence of pain and pulpal involvement), thereby assessing its concurrent construct validity. These hypotheses were based on the information obtained from the qualitative data described elsewhere [29].

\section{Responsiveness}

This was analysed using correlations between the mean change score at T2 and the global change score reported by the participant $(-1=$ worse, $0=$ same,$+1=$ better $)$ as recommended by the COSMIN group [18]. It was hypothesised that change score (difference between T0 and T2) would correlate with the global score, with those feeling there had been an improvement in their condition having a lower total score than those who felt they had stayed the same or felt worse. It was also hypothesised that those who felt that they had improved would have lower mean scores than those who felt their dental condition had deteriorated or remained unchanged following treatment.

\section{Results}

Stages 5, 6 and 7: Validity, reliability and responsiveness Of those who were approached to participate in this stage, only one child declined, giving a response rate of $99 \%$. A total of 202 participants were recruited over the 7 -month period. Two (1\%) participants did not complete CARIES-QC and therefore were eliminated from further analysis. There were 95 (47.5\%) males and 105 (52.5\%) females with a mean age of 8.1 (range $=5.0-16.0$ ) years. The majority of children identified themselves as being white British $(65 \%, n=130)$. The majority $(59.5 \%, n=$ 119) of participants lived in the most deprived quintile according to UK national IMD ranking scores [52]. Further demographic information is shown in Table 3.

Twenty-two (11\%) children were in the permanent dentition, $72(36 \%)$ in the primary dentition and 106 (53\%) were in the mixed dentition. Further details of caries experience are shown in Table 4. Anterior caries was present in 41 (20.5\%) of the participants. Pulpal involvement was present in $160(80 \%)$ and pain reported in 145 $(72.8 \%)$ of participants.

\section{Missing data}

At baseline, a total of 11 (5.5\%) participants had missing values for CARIES-QC and $17(8.5 \%)$ for $\mathrm{CPQ}_{11-}$ 14:ISF:16. Three (1.5\%) and nine (4.5\%) participants had
Table 3 Demographic characteristics of the participants $(n=200)$

\begin{tabular}{lll}
\hline Variable & Proportion & Number \\
\hline Gender & & 95 \\
Male & $47.5 \%$ & 105 \\
Female & $52.5 \%$ & \\
Ethnicity & & 31 \\
Asian background & $15.5 \%$ & 5 \\
Black background & $2.5 \%$ & 9 \\
Mixed background & $4.5 \%$ & 130 \\
White British background & $65.0 \%$ & 9 \\
Other background & $4.5 \%$ & 16 \\
Unknown background & $8.0 \%$ & \\
Socioeconomic status & & 119 \\
Most deprived & $59.5 \%$ & 37 \\
More deprived & $18.5 \%$ & 20 \\
Average & $10.0 \%$ & 13 \\
Less deprived & $6.5 \%$ & 11 \\
Least deprived & $5.5 \%$ & \\
\hline
\end{tabular}

greater than two missing values in CARIES-QC and $\mathrm{CPQ}_{11-14}: \mathrm{ISF} 16$ respectively and were therefore eliminated from the following analyses with the exception of the Rasch analysis. Those with more than two missing responses had generally omitted entire pages. Missing values were replaced with the participant's overall mean value. Where participants had omitted the global question, this was not replaced by a mean value and therefore correlations with the global score were not undertaken for these participants. There were no missing values at $\mathrm{T} 1$ and only one missing value at $\mathrm{T} 2$ in CARIES-QC. The missing value at T2 was replaced with the participant's overall mean value.

Table 4 Caries experience of included participants $(n=200)$

\begin{tabular}{llll}
\hline & Minimum & Maximum & Mean (SD) \\
\hline dmft & 0 & 16 & $6.24(3.45)$ \\
Number of carious primary teeth & 0 & 14 & $5.74(3.40)$ \\
Number of missing primary teeth & 0 & 10 & $0.27(1.15)$ \\
Number of filled primary teeth & 0 & 4 & $0.22(0.69)$ \\
DMFT & 0 & 13 & $1.57(2.18)$ \\
Number of carious permanent teeth & 0 & 9 & $1.38(1.77)$ \\
Number of missing permanent teeth & 0 & 4 & $0.05(0.38)$ \\
Number of filled permanent teeth & 0 & 7 & $0.13(0.74)$ \\
Total number of carious teeth & 1 & 14 & $6.01(3.27)$ \\
Total number of missing teeth & 0 & 10 & $0.27(1.12)$ \\
Total number of filled teeth & 0 & 7 & $0.28(0.89)$ \\
\hline
\end{tabular}

SD Standard deviation

dmft Total number of decayed, missing and filled primary teeth

DMFT Total number of decayed, missing and filled permanent teeth 
Analysis using the Rasch model

Two hundred participants were included in the Rasch analysis. One item ("feeling tired") had a disordered threshold and three items demonstrated misfit to the model ("taking medicine", "front teeth looking brown or black" and "being able to see holes"). No DIF was observed. Seven participants did not fit the Rasch model and were therefore removed from further Rasch analysis. This resulted in acceptable fit statistics (Additional file 2). The mean person location is -1.12 when the items are centred on zero. This demonstrates that the scale is targeted to a population with slightly more impacts than the participants in the present study, which may be due to the number of participants who reported no or low levels of impacts. Figure 2 shows the person-item threshold map and demonstrates that participants are distributed in a similar pattern to the items, indicating that the items measure the impacts of caries along the construct from least to most. As the items fit the Rasch model, a transformation from the raw score (possible range 0-24) to interval scaling is shown in Table 5.

\section{Interpretability}

As four items had been removed following previous analysis. The following analyses are based on the remaining 12-items. One hundred and ninety-seven participants were included in the analysis of CARIES-QC, three were excluded as they had omitted more than two questions.

At baseline, nine (4.6\%) participants scored the lowest possible score $(0)$ and one $(0.5 \%)$ the highest (24), which is within an acceptable range for floor and ceiling effects.
Table 5 Transformation of raw (ordinal) score to interval score

\begin{tabular}{|c|c|}
\hline Raw score & Interval score \\
\hline 0 & 0 \\
\hline 1 & 2.63 \\
\hline 2 & 4.50 \\
\hline 3 & 5.84 \\
\hline 4 & 6.90 \\
\hline 5 & 7.80 \\
\hline 6 & 8.60 \\
\hline 7 & 9.32 \\
\hline 8 & 10.00 \\
\hline 9 & 10.64 \\
\hline 10 & 11.26 \\
\hline 11 & 11.86 \\
\hline 12 & 12.45 \\
\hline 13 & 13.03 \\
\hline 14 & 13.62 \\
\hline 15 & 14.22 \\
\hline 16 & 14.84 \\
\hline 17 & 15.48 \\
\hline 18 & 16.17 \\
\hline 19 & 16.92 \\
\hline 20 & 17.76 \\
\hline 21 & 18.75 \\
\hline 22 & 19.96 \\
\hline 23 & 21.65 \\
\hline 24 & 24.00 \\
\hline
\end{tabular}

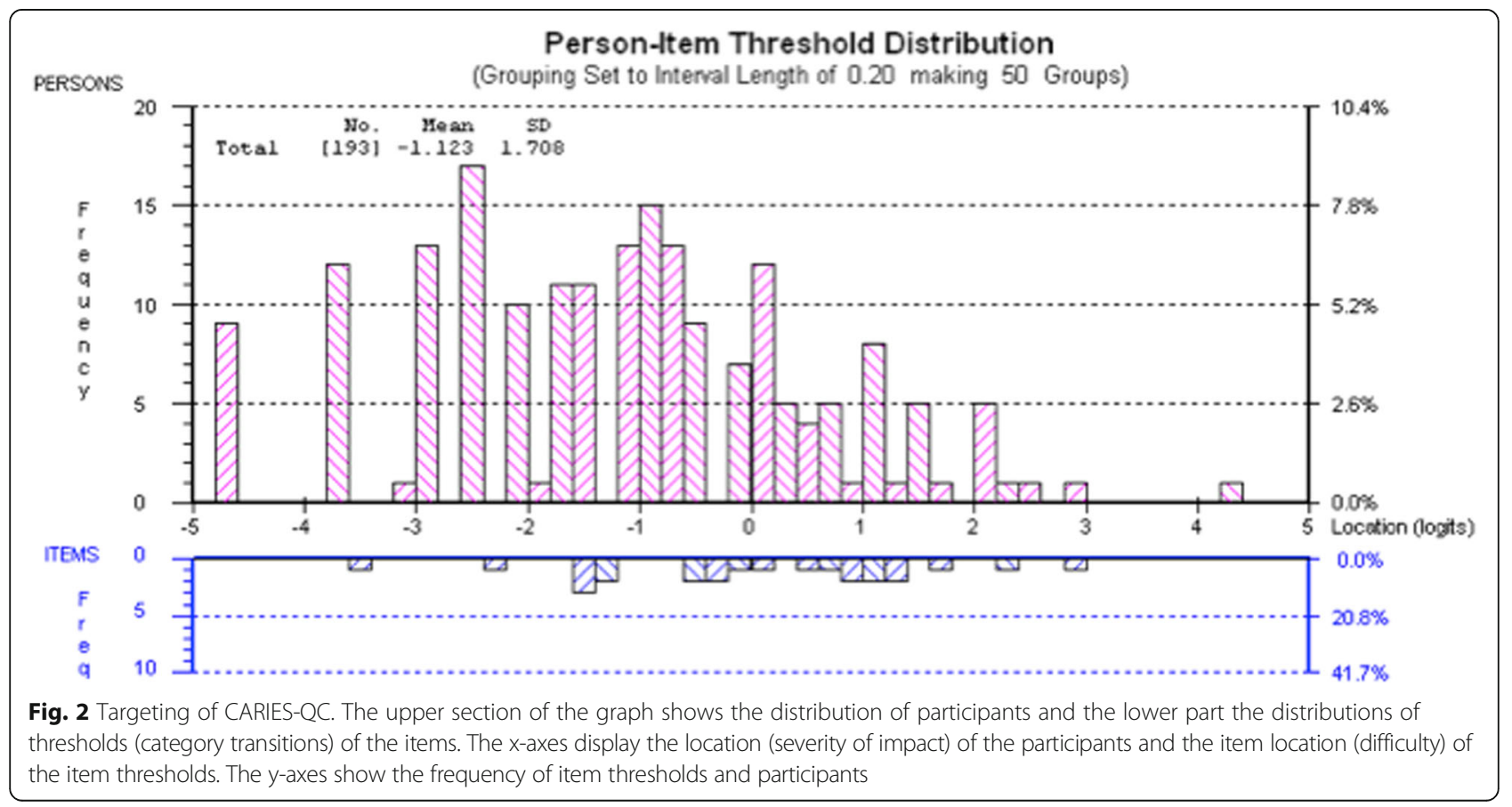


The mean (SD; range) raw score was 8.08 (5.52, 0-24) and the CIS mean score was 9.34. Mean CIS for the different subgroups are shown in Table 6. Statistically significant higher mean scores were found for children who reported pain $(\mathrm{CI}=2.63-5.19 ; p=<0.001)$ compared those who had not. This was also true for those who had anterior caries $(\mathrm{CI}=0.16-3.20 ; p=0.03)$ when compared with those without anterior caries and those who had pulpal involvement $(\mathrm{CI}=0.79-3.82 ; p=0.03)$ when compared with those without pulpal involvement. A statistically significant difference was found between ethnic groups $(\mathrm{CI}=-2.74$ to $-0.13 ; \mathrm{p}=0.03)$, with those from non-white British backgrounds having higher scores than those from white British backgrounds. This was despite there being no significant difference between the number of carious teeth, the presence of pain or pulpal involvement between subgroups.

At T1 $(n=71)$, the mean (SD; range) raw score was 6.30 (4.87; $0-20)$ with three $(4.5 \%)$ participants scoring the lowest possible score. The CIS mean (SD; range) score was 7.97 (4.09; 0-17.76). For the 31 participants who reported that they had experienced no change since T0, the mean (SD; range) CIS was 7.96 (3.55; 2.63-16.17). This contrasted with a lower mean (SD; range) CIS of 7.08 $(4.39 ; 0-17.76)$ in those who reported that their teeth felt better $(n=33)$ and a higher mean (SD; range) CIS of 12.14 (2.22; 8.6-14.84) in those who felt their teeth had deteriorated $(n=7)$.

The impact which was most commonly reported by participants at baseline was "food stuck" ( $n=173,87.5 \%)$ and the least reported impact was "interfering with schoolwork" ( $n=34,17.3 \%)$. The majority of items were reported by greater than $50 \%$ of participants. Interestingly, there were $62(31.5 \%)$ children who answered that they had experienced no pain. However, 53 (85\%) of these children reported other impacts related to their caries experience with CARIES-QC total scores ranging from 1 to 11 (mean=2.97). This compared with scores of $1-24$ (mean $=10.24)$ for those answering that they either had "a bit" or "a lot" of pain. A statistically significant difference in mean CIS was found between the pain and non-pain subgroups $(p=0.00 ; \mathrm{CI}=-4.89$ to -0.84$)$. At baseline, 64.5\% ( $n=127 / 196)$ reported that their teeth were "a bit" or "a lot" of a problem with respect to the global question.

\section{Internal consistency, reliability and construct validity of CARIES-QC}

Cronbach's alpha was found to be 0.9 . This did not increase if any items were deleted, as would be expected following the Rasch analysis which was used to confirm internal consistency of the items. Item total correlations ranged from 0.509 (food stuck) to 0.719 (eating carefully).
A total of 70 participants participated in the test-retest analysis at a mean (range) of 29 (3-127) days from T0. Thirty-one participants reported that their condition had remained stable. Those participants who had reportedly remained stable had similar clinical and demographic characteristics at baseline to the participants at T0. The ICC was 0.7 .

No order effect was present $(p=0.732)$. A strong correlation was found between CARIES-QC total and the global question $(r=0.734)(p<0.01)$. Weaker but significant $(p<0.01)$ correlations were found between the total CARIES-QC score and pain $(r=0.392)$, the total number of carious teeth $(r=0.188)$ and with the presence of pulpal involvement $(r=0.187)$. Further details are shown in Additional file 3 . Significant $(\mathrm{p}<0.01)$ correlations were also found between CARIES-QC total score and the total $\mathrm{CPQ}_{11-14}$-ISF:16 score $(r=0.733)$, the global oral health question from $\mathrm{CPQ}_{11-14}$-ISF:16 $(r=0.291)$ and life overall

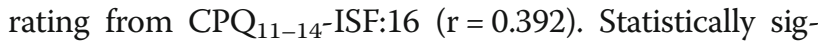
nificant correlations were found with CARIES-QC total score and all domains of $\mathrm{CPQ}_{11-14}$-ISF:16 with the highest correlation being between the oral symptoms $(r=0.646)$, functional limitations $(r=0.665)$ and emotional wellbeing $(r=0.630)$ domains.

\section{Responsiveness}

Data from 43 participants were available following a comprehensive course of treatment (T2). These participants had a similar profile to those included at TO, although a higher proportion of these post-treatment children had pulpal involvement at baseline. Their mean (range) age was $7.86(5.33-12.56)$ and $40.5 \%$ were male. The mean (range) dmft was $6.18(1-12)$ and mean (range) DMFT was 1.04 (0-4).

Of the children who participated at T2, $34(79.0 \%)$ reported an improvement since baseline, $6(14.0 \%)$ reported no change and $3(7.0 \%)$ reported a deterioration in their oral condition. The mean (SD; range) raw score was 4.09 (3.96; 0-16), with six participants (14.3\%) scoring the lowest possible score. Extraction of teeth under general anaesthesia (GA) was the most common treatment provided $(n=22,51.2 \%)$. The second most frequent treatment modality was provision of preformed metal crowns using the non invasive Hall Technique [53] (provided prior to the GA) in combination with XGA $(n=10,23.3 \%)$. A total of $32(74.4 \%)$ participants had some of their treatment provided under GA. The mean (range) time between the final treatment session and T2 and between T0 and T2 was $66.8(0-241)$ days and 138.23 (48-287) days respectively.

Impacts were reported in relation to all items following treatment. The most frequently reported impact at T2 was "food stuck" ( $n=27,62.8 \%)$, followed by "hurts" ( $n=17,39.5 \%)$. Responses of "a bit" or "a lot" to the 
Table 6 Mean, range and standard deviation of CARIES-QC baseline scores

\begin{tabular}{|c|c|c|c|c|}
\hline \multicolumn{2}{|l|}{ Participants/subgroups } & \multicolumn{3}{|c|}{ CARIES-QC interval score } \\
\hline Participants & Number (\%) & Mean score & Range & SD \\
\hline Overall & 197 & 9.34 & $0-24$ & 4.44 \\
\hline \multicolumn{5}{|l|}{ Gender } \\
\hline \multirow[t]{2}{*}{ Female } & 103 & 9.71 & $0-24$ & 4.59 \\
\hline & $(52.3 \%)$ & & & \\
\hline \multirow[t]{2}{*}{ Male } & 94 & 9.05 & $0-18.75$ & 4.28 \\
\hline & $(47.7 \%)$ & & & \\
\hline \multicolumn{5}{|l|}{ Age group } \\
\hline \multirow[t]{2}{*}{$5-7$ years } & 114 & 9.82 & $0-24$ & 4.51 \\
\hline & $(57.9 \%)$ & & & \\
\hline \multirow[t]{2}{*}{$8-11$ years } & 66 & 8.91 & $0-18.75$ & 4.55 \\
\hline & $(33.5 \%)$ & & & \\
\hline \multirow[t]{2}{*}{$12-16$ years } & 17 & 8.90 & $2.63-16.17$ & 3.49 \\
\hline & $(8.6 \%)$ & & & \\
\hline \multicolumn{5}{|l|}{ Pain } \\
\hline \multirow[t]{2}{*}{ Yes } & 142 & $10.49 a^{* *}$ & $0-24$ & 4.09 \\
\hline & $(72.1 \%)$ & & & \\
\hline \multirow[t]{2}{*}{ No } & 55 & 6.57 & $0-17.76$ & 4.10 \\
\hline & $(27.9 \%)$ & & & \\
\hline \multicolumn{5}{|l|}{ Pulpal involvement } \\
\hline \multirow[t]{2}{*}{ Yes } & 157 & $9.86 b^{*}$ & $0-24$ & 4.26 \\
\hline & $(79.7 \%)$ & & & \\
\hline \multirow[t]{2}{*}{ No } & 40 & 7.56 & $0-17.76$ & 4.72 \\
\hline & $(20.3 \%)$ & & & \\
\hline \multicolumn{5}{|l|}{ Anterior caries } \\
\hline \multirow[t]{2}{*}{ Yes } & 41 & $10.72 c^{*}$ & $0-24$ & 4.71 \\
\hline & $(20.8 \%)$ & & & \\
\hline \multirow[t]{2}{*}{ No } & 156 & 9.04 & 0-19.96 & 4.32 \\
\hline & $(79.2 \%)$ & & & \\
\hline \multicolumn{5}{|l|}{ Ethnicity } \\
\hline \multirow[t]{2}{*}{ White British background } & 130 & 8.91 & $0-18.75$ & 4.29 \\
\hline & $(66.0 \%)$ & & & \\
\hline \multirow[t]{2}{*}{ Other background } & 53 & $10.57 d^{*}$ & $0-24$ & 4.82 \\
\hline & $(34.0 \%)$ & & & \\
\hline \multicolumn{5}{|l|}{ Deprivation } \\
\hline \multirow[t]{2}{*}{ Deprivation group 1 (lowest) } & 67 & 9.20 & $0-24$ & 4.92 \\
\hline & $(34.0 \%)$ & & & \\
\hline \multirow[t]{2}{*}{ Deprivation group 2 (middle) } & 65 & 9.93 & 0-19.96 & 4.35 \\
\hline & $(33.0 \%)$ & & & \\
\hline \multirow[t]{2}{*}{ Deprivation group 3 (highest) } & 65 & 9.04 & $0-17.76$ & 4.02 \\
\hline & (33.0\%) & & & \\
\hline
\end{tabular}

$S D$ Standard deviation, $\mathrm{a}^{* *}=$ children who reported pain had significantly higher mean CARIES-QC interval score than those who did not report pain $(\mathrm{Cl}=2.63-5.19$; $p<0.01) ; b^{*}=$ children who had pulpal involvement had significantly higher mean CARIES-QC interval score than those who had no pulpal involvement $(C \mathrm{Cl}=0.79-3.82 ; p<0.05)$; $c^{*}=$ children with anterior caries had significantly higher mean CARIES-QC interval score than those who did not have anterior caries $(C l=0.16-3.20 ; p<0.05) ; d^{*}=$ children from non-white British backgrounds had significantly higher mean CARIES-QC interval score than those from white British backgrounds $(C \mathrm{Cl}=-2.74$ to $-0.13 ; p<0.05)$ 
CARIES-QC global question accounted for $30.2 \%(n=13)$ answers. With the exception of the item "interfering with schoolwork", the number of children who reported experience of each impact decreased between baseline and follow-up in those who reported an improvement. For those who reported improvement, the item "annoyed" was seen to have undergone the greatest reduction in frequency of reporting between baseline and follow-up (60.6\%), followed by "hurts" (45.5\%) and "eating on one side" (42.5\%). Comparisons with baseline data are shown in Table 7.

The mean (SD; range) raw score for those who reported an improvement $(n=34)$ was $2.94(2.89 ; 0-14)$ compared to $6.67(3.67 ; 2-12)$ for those who reported no change $(n=6)$ and $12.33(3.51 ; 9-16)$ for those who felt they were worse following treatment $(n=3)$. The mean difference in CIS between baseline and follow-up for those who felt they had improved was minus 4.42 (range $=$ minus 12.45 -plus $2.76 ; \mathrm{SD}=3.62$ ), thus indicating a MID of 4.42 points. There was a statistically significant difference between the mean score at baseline and follow-up in those who reported an improvement $(\mathrm{CI}=3.16-5.65 ; p=0.00)$. A strong statistically significant correlation $(\mathrm{CI}=3.16-5.66 ; p=0.01)$ was found between the GTJ and the CIS change score $(r=0.438$, Pearson correlation). Comparisons between the groups can be seen in Table 8 .

\section{Discussion}

This study aimed to develop and validate a caries-specific measure of OHRQoL for children. This was achieved through a systematic approach as recommended by Guyatt and colleagues involving an item response theory stage [54].

\section{Development of the measure}

The first stage sought to explore children's experiences of having dental caries. Children were found to be capable and willing to discuss the impacts they had experienced. Children generally discussed the impacts they had experienced in terms of their severity, rather than the frequency with which they occurred. This is an important finding as some of the existing measures of OHRQoL (CPQ and COHIP) rely on a frequency-based response format which does not appear to reflect how children describe their impacts. This tendency to discuss severity rather than frequency has been found by others who have utilised children's preferences to develop response formats $[55,56]$.

Conducting the analysis of face and content validity gave an insight into how children read and answer questions. The analysis of face validity was essential as it revealed problems with the way some questions were worded. In particular, the way children answered the original global question "Overall how healthy are your teeth?", was interesting as it appeared to have little to do with the condition of their teeth or the symptoms they had experienced. It should be noted that this wording is similar to that used in the global question relating to oral health in CPQ. This may explain why previous studies have found relatively low correlations between the global oral health question in CPQ and total CPQ score in children with caries $[9,10,12,36,57-59]$. In the present study, however, there was a strong $(r=0.734)$ correlation between the global oral health question in CARIES-QC and the total CARIES-QC score. This was not seen with the CPQ global oral health question and may indicate that although the global questions of CARIES-QC and CPQ both seek to address the same construct, they do not appear to ask the same question.

\section{Evaluation of the measure}

Children as young as 5 years of age were able to complete CARIES-QC, with their parents or one of the research team helping them to read the questions. This concurs with previous observations that five-year-old children are able to reliably report their health-related quality of life given the opportunity to do so using an age-appropriate instrument [60].

Construct validity was tested using correlations with the total CARIES-QC score and clinical data, the global questions of CARIES-QC and CPQ $11-14$-ISF:16 total score. CARIES-QC had stronger correlations with clinical data than $\mathrm{CPQ}_{11-14}$-ISF:16 indicating that it may be more sensitive to assessing those impacts specifically associated with dental caries. $\mathrm{CPQ}_{11-14}$-ISF:16 was designed to be generic and be able to evaluate the impacts of a variety of oral conditions, thus it may be that some of the included items are irrelevant to children with caries.

Rasch analysis allowed a unidimensional measure to be produced and identified items which did not fit the mathematical model. Indeed, the question relating to taking medicine, was one for which many children seemed to seek confirmation from their parents. Children appeared to be unsure if they had taken medicine for problems with their teeth and it may be that children are often given analgesia for other problems and therefore cannot remember why they were given it. This question was subsequently removed following Rasch analysis, as it had poor fit statistics, indicating that, it did not work as intended. A similar finding occurred for the items relating to aesthetics. This in hindsight is perhaps not surprising as these aesthetic aspects were identified as a separate theme in the qualitative analysis [29].

A three-point Likert scale was adopted as the response format for CARIES-QC. This approach is in keeping with other studies which have used a three-point scale $[61,62]$. However, it is acknowledged that whilst 
Table 7 Number and proportion of participants responding positively ("a bit" or "a lot") to each item in CARIES-QC following treatment at baseline and follow-up

\begin{tabular}{|c|c|c|}
\hline Item and response & $\begin{array}{l}\text { Proportion (number) with } \\
\text { impact at baseline }(n=197)\end{array}$ & $\begin{array}{l}\text { Proportion (number) with } \\
\text { impact at follow-up }(n=43)\end{array}$ \\
\hline Food stuck & $87.8 \%(173)$ & $62.8 \%(27)$ \\
\hline A bit & $55.3 \%(109)$ & $51.2 \%(22)$ \\
\hline A lot & $32.5 \%(64)$ & $11.6 \%(5)$ \\
\hline Hurts & $68.5 \%(135)$ & $39.5 \%(17)$ \\
\hline A bit & $51.3 \%(101)$ & $37.2 \%(16)$ \\
\hline A lot & $17.3 \%(34)$ & $2.3 \%(1)$ \\
\hline Eating on one side & $62.4 \%(123)$ & $32.6 \%(14)$ \\
\hline A bit & $36.5 \%(72)$ & $16.3 \%(7)$ \\
\hline A lot & $25.9 \%(51)$ & $16.3 \%(7)$ \\
\hline Cried & $61.4 \%(121)$ & $32.6 \%(14)$ \\
\hline A bit & $47.7 \%(94)$ & $27.9 \%(12)$ \\
\hline A lot & $13.7 \%(27)$ & $4.7 \%(2)$ \\
\hline Annoyed & $59.9 \%(118)$ & $18.6 \%(8)$ \\
\hline A bit & $40.6 \%(80)$ & $16.3 \%(7)$ \\
\hline A lot & $19.3 \%(38)$ & $2.3 \%(1)$ \\
\hline Eating carefully & $56.3 \%(111)$ & $37.2 \%(16)$ \\
\hline A bit & $38.1 \%(75)$ & $30.2 \%(13)$ \\
\hline A lot & $18.3 \%(36)$ & $7.0 \%(3)$ \\
\hline Difficult to eat some foods & $56.3 \%(111)$ & $37.2 \%(16)$ \\
\hline A bit & $46.7 \%(92)$ & $34.9 \%(15)$ \\
\hline A lot & $9.6 \%(19)$ & $2.3 \%(1)$ \\
\hline Eating slowly & $44.2 \%(87)$ & $27.9 \%(12)$ \\
\hline A bit & $33.5 \%(66)$ & $18.6 \%(8)$ \\
\hline A lot & $10.7 \%(21)$ & $9.3 \%(4)$ \\
\hline Brushing teeth & $42.6 \%(84)$ & $18.6 \%(8)$ \\
\hline A bit & $32.0 \%(63)$ & $18.6 \%(8)$ \\
\hline A lot & $10.7 \%(21)$ & 0 \\
\hline Feeling cross & $40.6 \%(80)$ & $13.9 \%(6)$ \\
\hline A bit & $28.4 \%(56)$ & $11.6 \%(5)$ \\
\hline A lot & $12.2 \%(24)$ & $2.3 \%(1)$ \\
\hline Kept awake & $32.5 \%(64)$ & $11.6 \%(5)$ \\
\hline A bit & $27.4 \%(54)$ & $9.3 \%(4)$ \\
\hline A lot & $5.1 \%(10)$ & $2.3 \%(1)$ \\
\hline Interfering with schoolwork & $17.3 \%(34)$ & $11.6 \%(5)$ \\
\hline A bit & $14.7 \%(29)$ & $7.0 \%(3)$ \\
\hline A lot & $2.5 \%(5)$ & $4.7 \%(2)$ \\
\hline Global question & $64.5 \%(127)$ & $30.2 \%(13)$ \\
\hline A bit & $49.0 \%(96)$ & $27.9 \%(12)$ \\
\hline A lot & $15.7 \%(31)$ & $2.3 \%(1)$ \\
\hline
\end{tabular}

Italicised figures indicate the overall proportion (number) responding positively to each item

younger children may express a preference for a three-point scale, older children may prefer more options [63]. However, as CARIES-QC was designed to be used over a wide age range and with children who may have low literacy levels or where English may not be their first language, it was decided that a three-point 
Table 8 Mean (range) and change scores calculated using CARIES-QC interval scores $(n=42)$

\begin{tabular}{llll}
\hline $\begin{array}{l}\text { Reported condition } \\
\text { at follow-up }\end{array}$ & $\begin{array}{l}\text { Mean (range) CARIES-QC } \\
\text { interval score at baseline }\end{array}$ & $\begin{array}{l}\text { Mean (range) CARIES-QC } \\
\text { interval score at follow-up }\end{array}$ & $\begin{array}{l}\text { Mean (range) } \\
\text { change score }\end{array}$ \\
\hline $\begin{array}{l}\text { All follow-up participants }(n=43) \\
\begin{array}{l}\text { Improved } \\
(n=34)\end{array}\end{array}$ & $\begin{array}{l}9.46(2.63-19.96) \\
9.33(2.63-19.96)\end{array}$ & $\begin{array}{l}5.99(0-5.48) \\
4.89(0-13.62)\end{array}$ & -3.48 (minus 12.45-4.10) \\
$\begin{array}{l}\text { Unchanged } \\
(n=6)\end{array}$ & $8.32(4.5-12.45)$ & $8.74(4.5-12.45)$ & 0.42 (minus 12.45-2.76) \\
$\begin{array}{l}\text { Deteriorated } \\
(n=3)\end{array}$ & $13.52-4.10)$ \\
\hline
\end{tabular}

scale would reduce participant burden and allow participation from all demographic groups. With the exception of one question ("feeling tired"), Rasch analysis demonstrated that children were able to distinguish between the three different response options. There is some debate about the number of response options which should be used, with some suggesting sensitivity increases with increasing number of options, whilst others argue that reliability is increased with fewer response options [64]. It has been found that the number of response options may have less of an effect where the items are homogenous, such as in a unidimensional scale [64]. Despite the use of a three-point scale, CARIES-QC was able to differentiate between participants with differing clinical presentations and to evaluate changes following treatment.

For those children reporting an improvement following a course of treatment, the impact which decreased most was "feeling annoyed" in those who reported an improvement. Reduction in this emotional aspect warrants further thought, as one might have expected functional impacts to be most improved following treatment. It may reflect how children perceive chronic dental pain: some children with extensive dental caries do not complain of pain, perhaps because they have had chronic pain for many years and do not recognise this as pain when compared to more acute symptoms. Therefore, a more accurate description from their perspective may be that their teeth are less "annoying".

This finding also demonstrates the value of including all aspects that are important to patients and not just focusing on functional aspects. Large reductions were also found in the impacts "crying", "hurts", "brushing teeth", "eating on one side" and "feeling cross", demonstrating the breadth of impacts which were perceived to have reduced following dental treatment. Not surprisingly, given that the majority of patients had multiple teeth extracted as part of their treatment, improvements relating to eating were less marked.

As CARIES-QC is a disease-specific QoL measure, it contains items which are most relevant to children with caries. Thus it is more sensitive to any specific changes which may occur following intervention, as the "noise" from irrelevant questions is reduced [17]. Despite the limited number of participants included in responsiveness evaluation stage, changes which correlated with the GTJ were found. It would be hoped that CARIES-QC could therefore identify changes which may occur as the result of different interventions for dental caries.

\section{Limitations}

A key aim was to retain the language children used in the development stage in the definitive measure. Therefore, while the measure reflects the language used by children resident in Sheffield, it remains to be seen whether this language is appropriate outwith this geographical location. Attempts were made to ensure local colloquialisms were not included and certainly it would appear that the language the children used to describe pain was similar to that found throughout the UK and the US [65-67]. The CHU9D, a preference-based QoL measure, which was also developed in Sheffield, incorporates similar words in its response format and has been used successfully in other parts of the UK and Australia and New Zealand [68-70]. Nonetheless, it would be prudent to conduct preliminary evaluations before applying the measure in other English speaking countries.

CARIES-QC is designed for use with children in the age range of 5-16 years, as the impacts that children described were similar regardless of age. The items were worded using the language used by the youngest children to ensure that it could be understood by all. Further qualitative enquiry with children in the permanent dentition is required to assess whether items relating to aesthetic impacts would be a useful addition as this may be something which is more important to children in this older age group.

CARIES-QC had good construct validity and unidimensionality in this population. However, it is acknowledged that only two children were recruited from primary care, and the participants had a high caries prevalence and extensive disease. Although the majority of participants had extensive disease ( $80 \%$ had pulpal involvement), a number reported that they had not experienced pain. It is possible, therefore, that the findings may be different in a population with less extensive disease. However, it should be recognised that the measure 
was primarily designed to evaluate change in those who require interventions for dental caries and not to discriminate between children with different levels of disease. Therefore, it is likely that those who require treatment, will have some impacts which may improve following an intervention.

The ICC for test-retest reliability was slightly lower than ideal, and this may be due to the length of time between the two administrations of the measure, the low number of children who felt that their oral condition had remained stable or the fact that use of a three-point response scale may reduce test-retest reliability [64]. Testing of this element in a larger population with a shorter and more consistent time period between administrations is required.

Responsiveness was only tested in a very small proportion of the participants $(n=43)$ to give an indication of whether it responded as expected. However, the initial results are promising with those who felt they had improved having lower mean scores than those who did not report an improvement. An estimation of the MID was made for this population, however, additional testing in a larger population is required to further test the responsiveness of the measure. Larger populations would also allow the calculation of effect sizes and the standardised response mean, which would aid the clinical interpretation and calculation of future sample sizes [54].

\section{Conclusion}

In conclusion, children's input allowed the development of a valid, reliable and responsive child-centred caries-specific quality of life measure. CARIES-QC now offers a much needed tool to evaluate which interventions for dental caries are most effective in reducing impacts from the child's perspective.

\section{Additional files}

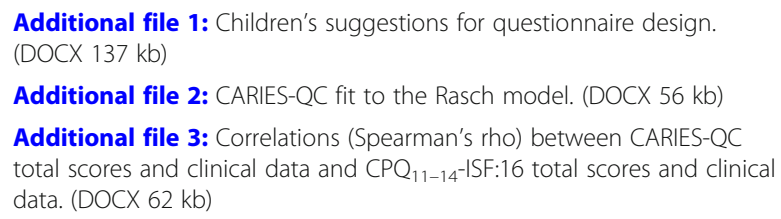

\footnotetext{
Abbreviations

CARIES-QC: Caries Impacts and Experiences Questionnaire for Children; CCDH: Charles Clifford Dental Hospital; Cl: Confidence interval; CIS: CARIESQC interval scale; COHIP: Child Oral Health Impact Profile; C-OIDP: Child Oral Impacts on Daily Performances; COSMIN: Consensus-based Standards for the selection of health Measurement Instruments; CPQ: Child Perceptions Questionnaire; DMFT: Decayed, missing and filled permanent teeth; FG : Fiona Gilchrist, Principal Investigator; ICC: Intraclass correlation coefficient; IMD: Index of Multiple Deprivation; IRT: Item response theory; OHRQoL: Oral health-related quality of life; SD: Standard Deviation
}

\section{Acknowledgements}

We thank the children and their families for their invaluable contribution to this study. Our thanks also to Professor Sarah Baker for statistical advice and for her comments on the first draft of this manuscript and to our colleagues at Firth Park Clinic, Sheffield.

\section{Funding}

FG was funded by a National Institute for Health Research Doctoral Research Fellowship (DRF-2012-05-466). This paper presents independent research funded by the National Institute for Health Research (NIHR). The views expressed are those of the authors and not necessarily those of the NHS, the NIHR or the Department of Health. The funder was not involved in the design of the study or the collection, analysis, or interpretation of the data or preparation of the manuscript.

\section{Availability of data and materials}

The datasets generated and/or analysed during the current study are available from the corresponding author on reasonable request. CARIES-QC is available on request from the authors by email or at https://www.sheffield.ac.uk/dentalschool/research/create\#tab01.

\section{Authors' contributions}

FG led the study, participated in the design of the study, collected and analysed data and prepared the first draft of the paper. HDR participated in the design of the study, collected data and helped with drafting the manuscript. CD participated in the design of the study, collected data and helped draft the manuscript. ZM participated in the design of the study, analysed data and helped draft the manuscript. All authors have read and approved the final manuscript.

\section{Ethics approval and consent to participate}

Ethical approval was granted by the South Yorkshire Research Ethics Committee (Reference number: 11/H1310/3). All participants gave verbal and written assent to participate and their parents gave verbal and written consent for their child to participate.

\section{Consent for publication \\ Not applicable.}

\section{Competing interests}

The authors declare that they have no competing interests.

\section{Publisher's Note}

Springer Nature remains neutral with regard to jurisdictional claims in published maps and institutional affiliations.

Received: 19 April 2017 Accepted: 12 November 2018 Published online: 04 December 2018

\section{References}

1. Kassebaum NJ, Bernabe E, Dahiya M, Bhandari B, Murray CJ, Marcenes W. Global burden of untreated caries: a systematic review and Metaregression. J Dent Res. 2015;94(5):650-8.

2. Pau A, Khan SS, Babar MG, Croucher R. Dental pain and care-seeking in 1114-yr-old adolescents in a low-income country. Eur J Oral Sci. 2008;116(5): 451-7.

3. Krisdapong S, Prasertsom P, Rattanarangsima K, Sheiham A. Relationships between oral diseases and impacts on Thai schoolchildren's quality of life: evidence from a Thai national oral health survey of 12- and 15-year-olds. Community Dent Oral Epidemiol. 2012;40(6):550-9.

4. Krisdapong S, Prasertsom P, Rattanarangsima K, Sheiham A. Impacts on quality of life related to dental caries in a national representative sample of Thai 12- and 15-year-olds. Caries Res. 2013;47(1):9-17.

5. Naidoo S, Sheiham A, Tsakos G. The relation between oral impacts on daily performances and perceived clinical oral conditions in primary school children in the Ugu District, Kwazulu Natal, South Africa. SADJ. 2013;68(5):214-8.

6. Basavaraj P, Sunil MK, Nagarajappa R, Ashish S, Ramesh G. Correlation between Oral health and child-OIDP index in 12- and 15-year-old children from Modinagar, India. Asia Pac J Public Health. 2013;26(4):390-400. 
7. Broder HL, Wilson-Genderson M. Reliability and convergent and discriminant validity of the child Oral health impact profile (COHIP Child's version). Community Dent Oral Epidemiol. 2007;35(Suppl 1):20-31.

8. Brown A, Al-Khayal Z. Validity and reliability of the Arabic translation of the child oral-health-related quality of life questionnaire (CPQ11-14) in Saudi Arabia. Int J Paediatr Dent. 2006;16(6):405-11.

9. Gururatana O, Baker S, Robinson PG. Psychometric properties of long and short forms of the child perceptions questionnaire (CPQ11-14) in a Thai population. Community Dent Health. 2011;28(3):232-7.

10. Kolawole KA, Otuyemi OD, Oluwadaisi AM. Assessment of oral healthrelated quality of life in Nigerian children using the child perceptions questionnaire (CPQ 11-14). Eur J Paediatr Dent. 2011;12(1):55-9.

11. Marshman Z, Rodd H, Stern M, Mitchell C, Locker D, Jokovic A, Robinson PG. An evaluation of the child perceptions questionnaire in the UK. Community Dent Health. 2005;22(3):151-5.

12. Robinson PG, Nalweyiso N, Busingye J, Whitworth J. Subjective impacts of dental caries and fluorosis in rural Ugandan children. Community Dent Health. 2005;22(4):231-6.

13. Gilchrist F, Rodd H, Deery C, Marshman Z. Assessment of the quality of measures of child oral health-related quality of life. BMC Oral Health. 2014;14:40.

14. Cunnion DT, Spiro A 3rd, Jones JA, Rich SE, Papageorgiou CP, Tate A, Casamassimo P, Hayes C, Garcia RI. Pediatric oral health-related quality of life improvement after treatment of early childhood caries: a prospective multisite study. J Dent Child. 2010;77(1):4-11.

15. Locker $\mathrm{D}$. The burden of oral disorders in a population of older adults. Community Dent Health. 1992;9(2):109-24.

16. Locker D, Slade G. Association between clinical and subjective indicators of oral health status in an older adult population. Gerodontology. 1994;11(2):108-14.

17. Wiebe S, Guyatt G, Weaver B, Matijevic S, Sidwell C. Comparative responsiveness of generic and specific quality-of-life instruments. J Clin Epidemiol. 2003;56(1):52-60.

18. Mokkink LB, Terwee CB, Patrick DL, Alonso J, Stratford PW, Knol DL, Bouter $L M$, de Vet HC. The COSMIN checklist for assessing the methodological quality of studies on measurement properties of health status measurement instruments: an international Delphi study. Qual Life Res. 2010;19(4):539-49.

19. Traebert J, Foster Page LA, Thomson WM, Locker D. Differential item functioning related to ethnicity in an oral health-related quality of life measure. Int J Paediatr Dent. 2010;20(6):435-41.

20. Yau DT, Wong MC, Lam KF, McGrath C. Evaluation of psychometric properties and differential item functioning of 8-item child perceptions questionnaires using item response theory. BMC Public Health. 2015;15(1):792.

21. Yau DTW, Wong MCM, Lam KF, McGrath C. Longitudinal measurement invariance and explanatory IRT models for adolescents' oral health-related quality of life. Health Qual Life Outcomes. 2018;16(1):60.

22. Abanto J, Tsakos G, Ardenghi TM, Paiva SM, Raggio DP, Sheiham A, Bonecker M. Responsiveness to change for the Brazilian scale of Oral health outcomes for 5-year-old children (SOHO-5). Health Qual Life Outcomes. 2013;1 1:137.

23. Amato JN, Barbosa TS, Kobayashi FY, Gaviao MB. Changes in the oral-healthrelated quality of life of Brazilian children after an educational preventive programme: an 1-month longitudinal evaluation. Int J Dent Hyg. 2014;12(3): 226-33.

24. de Paula JS, Sarracini KL, Meneghim MC, Pereira AC, Ortega EM, Martins NS, Mialhe FL. Longitudinal evaluation of the impact of dental caries treatment on oral health-related quality of life among schoolchildren. Eur J Oral Sci. 2015;123(3):173-8.

25. Turton BJ, Thomson WM, Foster Page LA, Saub R, Ishak AR. Responsiveness of the child perceptions Questionnaire11-14 for Cambodian children undergoing basic dental care. Int J Paediatr Dent. 2015;25(1):2-8.

26. Locker D, Allen F. What do measures of 'oral health-related quality of life' measure? Community Dent Oral Epidemiol. 2007;35(6):401-11.

27. Guyatt GH, Bombardier C, Tugwell PX. Measuring disease-specific quality of life in clinical trials. CMAJ. 1986;134(8):889-95.

28. Sandelowski M. Sample size in qualitative research. Res Nurs Health. 1995; 18(2):179-83.

29. Gilchrist F, Marshman Z, Deery C, Rodd HD. The impact of dental caries on children and young people: what they have to say? Int J Paediatr Dent. 2015;25(5):327-38.

30. Prout A, James A. A new paradigm for the sociology of childhood: provenance, provision and problems. In: James A, Prout A, editors. Constructing and Reconstructing Childhood. Edn. London: Falmer Press; 1998. p. 7-32.
31. Holland S, Renold E, Ross N, Hillman A. The everyday lives of children in care: using a sociological perspective to inform social work practice. In: NCRM Working Paper. ESRC National Centre for research methods; 2008.

32. Ritchie J, Spencer L. Qualitative data analysis for applied policy research. In: Bryman A, Burgess R, editors. Analyzing Qualitative Data. New York: Routledge; 1994.

33. Ritchie J, Spencer L, O"Connor W. Carrying out qualitative analysis. Thousand Oaks: CA: SAGE; 2003.

34. Broder HL, McGrath C, Cisneros GJ. Questionnaire development: face validity and item impact testing of the child Oral health impact profile. Community Dent Oral Epidemiol. 2007;35:8-19.

35. Griffiths AM, Nicholas D, Smith C, Munk M, Stephens D, Durno C, Sherman PM. Development of a quality-of-life index for pediatric inflammatory bowel disease: dealing with differences related to age and IBD type. J Pediatr Gastroenterol Nutr. 1999;28(4):S46-52.

36. Jokovic A, Locker D, Stephens M, Kenny D, Tompson B, Guyatt G. Validity and reliability of a questionnaire for measuring child oral-health-related quality of life. J Dent Res. 2002;81(7):459-63.

37. Mallinson S. Listening to respondents: a qualitative assessment of the shortform 36 health status questionnaire. Soc Sci Med. 2002;54(1):11-21.

38. Marshman Z, Gibson BJ, Benson PE. Is the short-form child perceptions questionnaire meaningful and relevant to children with malocclusion in the UK? J Orthod. 2010;37(1):29-36.

39. Cano SJ, Hobart JC. The problem with health measurement. Patient Prefer Adherence. 2011:5:279-90.

40. Jokovic A, Locker D, Guyatt G. Short forms of the Child Perceptions Questionnaire for 11-14-year-old children (CPQ11-14): development and initial evaluation. Health Qual Life Outcomes. 2006:4:4.

41. Foster Page LA, Boyd D, Thomson WM. Do we need more than one child perceptions questionnaire for children and adolescents? BMC Oral Health. 2013;13:26.

42. Masters G. Rasch model for partial credit scoring. Psychometrika. 1982;47: 149-74.

43. Andrich D, Lyne A, Sheridon B, Luo G. RUMM 2030. In: Perth: RUMM Laboratory; 2009.

44. GeoConvert [http://geoconvert.mimas.ac.uk]

45. Shrive FM, Stuart H, Quan H, Ghali WA. Dealing with missing data in a multi-question depression scale: a comparison of imputation methods. BMC Med Res Methodol. 2006;6:57.

46. Tennant A, Conaghan PG. The Rasch measurement model in rheumatology: what is it and why use it? When should it be applied, and what should one look for in a Rasch paper? Arthritis Rheum. 2007;57(8):1358-62.

47. Linacre JM. Sample size and item calibration [or person measure] stability. In: Rasch Measurement Transactions vol 7; 1994. p. 328.

48. Kersten $P$, White PJ, Tennant A. Is the pain visual analogue scale linear and responsive to change? An exploration using Rasch analysis. PLoS One. 2014; 9(6):e99485.

49. Svensson E. Guidelines to statistical evaluation of data from rating scales and questionnaires. J Rehabil Med. 2001;33(1):47-8.

50. Tennant A, McKenna SP, Hagell P. Application of Rasch analysis in the development and application of quality of life instruments. Value Health. 2004;7(Suppl 1):S22-6.

51. Terwee $C B$, Bot SD, de Boer MR, van der Windt DA, Knol DL, Dekker J, Bouter LM, de Vet HC. Quality criteria were proposed for measurement properties of health status questionnaires. J Clin Epidemiol. 2007;60(1):34-42.

52. McLennan D, Barnes H, Noble M, Davies J, Garratt E, Dibben C. In: Edited by government DoCaL, editor. The English indices of deprivation 2010. London: Office of National Statistics; 2011.

53. Innes NP, Evans DJ, Stirrups DR. The hall technique; a randomized controlled clinical trial of a novel method of managing carious primary molars in general dental practice: acceptability of the technique and outcomes at 23 months. BMC Oral Health. 2007;7:18.

54. Guyatt G, Walter $S$, Norman G. Measuring change over time: assessing the usefulness of evaluative instruments. J Chronic Dis. 1987:40(2):171-8.

55. Carlton J. Developing the draft descriptive system for the child amblyopia treatment questionnaire (CAT-Qol): a mixed methods study. Health Qual Life Outcomes. 2013;11:174.

56. Stevens K. Developing a descriptive system for a new preference-based measure of health-related quality of life for children. Qual Life Res : an international journal of quality of life aspects of treatment, care and rehabilitation. 2009;18(8):1105-13. 
57. Aguilar-Diaz F-C, Irigoyen-Camacho M-E. Validation of the CPQ(8-10ESP) in Mexican school children in urban areas. Med Oral Patol Oral Cir Bucal. 2011; 16(3):E430-5.

58. Goursand D, Paiva SM, Zarzar PM, Ramos-Jorge ML, Cornacchia GM, Pordeus IA, Allison PJ. Cross-cultural adaptation of the child perceptions questionnaire 11-14 (CPQ11-14) for the Brazilian Portuguese language. Health \& Quality of Life Outcomes. 2008;6:2.

59. Jokovic A, Locker D, Tompson B, Guyatt G. Questionnaire for measuring oral health-related quality of life in eight- to ten-year-old children. Pediatr Dent. 2004;26(6):512-8

60. Varni JW, Limbers CA, Burwinkle TM. How young can children reliably and validly self-report their health-related quality of life?: an analysis of 8,591 children across age subgroups with the PedsQL 4.0 Generic Core Scales. Health Qual Life Outcomes. 2007;5:1.

61. Carlton J. Refinement of the child amblyopia treatment questionnaire (CATQoL) using Rasch analysis. In: HEDS discussion paper; 2013.

62. Varni JW, Seid M, Kurtin PS. PedsQL 4.0: reliability and validity of the pediatric quality of life inventory version 4.0 generic core scales in healthy and patient populations. Med Care. 2001;39(8):800-12.

63. Detmar SB, Bruil J, Ravens-Sieberer U, Gosch A, Bisegger C. European kg: the use of focus groups in the development of the KIDSCREEN HRQL questionnaire. Qual Life Res. 2006;15(8):1345-53.

64. Weng L-J. Impact of the number of response categories and anchor labels on coefficient alpha and test-retest reliability. Educ Psychol Meas. 2004;64(6): 956-72.

65. Franck L, Noble G, Liossi C. Translating the tears: parents' use of behavioural cues to detect pain in normally developing young children with everyday minor illnesses or injuries. Child Care Health Dev. 2010;36(6):895-904.

66. Mills NM. Pain behaviors in infants and toddlers. J Pain Symptom Manag. 1989:4(4):184-90

67. Stanford EA, Chambers $C T$, Craig KD. A normative analysis of the development of pain-related vocabulary in children. Pain. 2005;1 14(1-2):278-84.

68. Canaway AG, Frew EJ. Measuring preference-based quality of life in children aged 6-7 years: a comparison of the performance of the CHU-9D and EQ5D-Y--the WAVES pilot study. Qual Life Res. 2013;22(1):173-83.

69. Page LA, Thomson WM, Marshman Z, Stevens KJ. The potential of the child health utility $9 \mathrm{D}$ index as an outcome measure for child dental health. BMC Oral Health. 2014;14:90.

70. Stevens K, Ratcliffe J. Measuring and valuing health benefits for economic evaluation in adolescence: an assessment of the practicality and validity of the child health utility 9D in the Australian adolescent population. Value Health. 2012;15(8):1092-9.

Ready to submit your research? Choose BMC and benefit from:

- fast, convenient online submission

- thorough peer review by experienced researchers in your field

- rapid publication on acceptance

- support for research data, including large and complex data types

- gold Open Access which fosters wider collaboration and increased citations

- maximum visibility for your research: over $100 \mathrm{M}$ website views per year

At $\mathrm{BMC}$, research is always in progress.

Learn more biomedcentral.com/submissions 